\title{
O CUIDADO E A PERCEPÇÃO SENSÍVEL DO AMBIENTE HOSPITAR
}

\author{
Aline Cristina Calcada de Oliveira ${ }^{1}$, Augusto Luis Medeiros Amaral ${ }^{2}$, Cláudio Tarouco de Azevedo ${ }^{3}$
}

Palavras-Chave: cuidado sensível, ambiente hospitalar, ética, corpo, intervenção.

Este artigo é fruto das reflexões oriundas de intervenções em educação ambiental desenvolvidas durante a 35a Semana Riograndina de Enfermagem no Hospital Universitário da Universidade Federal do Rio Grande - FURG, no primeiro semestre de 2011. Sua temática aponta para um novo olhar sobre o processo saúde-doença, buscando estratégias de ressignificação do ambiente hospitalar através de um cuidado de enfermagem mais sensível. Para tanto, propõe-se, dentro de uma ética interventiva, trazer o afeto para as relações, chamando a atenção para uma nova concepção de vida, além da lógica capitalista. Tais intervenções engendram-se como práticas educativas ambientais a partir de processos multidisciplinares. As mesmas envolvem diferentes campos do saber, não menos passíveis de serem articulados, quais sejam: Saúde, Teatro (clown), Artes Visuais (audiovisuais).

\section{A qualidade das relações no ambiente hospitalar}

O cuidado de enfermagem nesse novo milênio terá o desafio de oxigenar não só as células de nossos pacientes, mas principalmente as mentes e os corações dos detentores do conhecimento. 0 fazer de cada profissional da saúde, seus corpos, seus pensamentos, angústias, anseios e necessidades estão relacionados com o processo saúde-doença. Uma das grandes fragilidades das escolas formadoras de medicina e enfermagem é justamente transpor o paradigma de um conhecimento técnico científico arraigado em um discurso instituído. A singularidade de cada pessoa, a capacidade humana de inventar, criar soluções e produzir novas possibilidades de existência parecem não ser levadas suficientemente a sério.

Deixamos escapar o fio condutor que dá um sentido às nossas vidas além da doença e da morte. Precisamos enfrentar a lógica doentia que procura nos escravizar através do consumo imposto pela mídia, estimulando-nos a um estilo de vida de como "devemos ser". Com isso, o movimento midiático das grandes corporações dos meios de comunicação procura cercear nosso jeito de ser e estar em detrimento de experimentarmos outros devires, da aventura de vir a ser o que ainda não somos. Um exemplo disso é que gravitamos incessantemente em torno da doença.

Estamos a serviço da patologia quando nossa função primordial é preveni-la. Contentamonos em tratar as conseqüências dos males humanos e transformar nosso dia-a-dia no ambiente hospitalar em uma saga interminável de queixas e reclamações. Talvez não percebamos que estamos tão ou até mesmo mais doentes do que as pessoas enfermas as quais cuidamos. Utilizamos nosso conhecimento para impregná-las com um discurso de que não podemos continuar assim, embora dia após dia fechemos os olhos para não enxergar as causas e sim o

\footnotetext{
${ }^{1}$ Doutoranda no Programa de Pós-Graduação em Educação Ambiental (PPGEA) da Universidade Federal do Rio Grande - FURG. Rua Santa Catarina, 647 - CEP 96211-600 - Rio Grande/RS.

${ }^{2}$ Doutorando no Programa de Pós-Graduação em Educação Ambiental (PPGEA) da Universidade Federal do Rio Grande - FURG. Rua Ceslau Mario Biezanko, 51 Casa 01 - CEP 96080-420 - Pelotas/RS.

${ }^{3}$ Doutorando no Programa de Pós-Graduação em Educação Ambiental (PPGEA) da Universidade Federal do Rio Grande - FURG. Avenida 15 de novembro, 620 - CEP 96211-590 - Rio Grande/RS.
} 
diagnóstico atual e seus efeitos. Assim nos colocamos como engrenagens substituíveis num sistema que lucra com a doença, onde cada pessoa é um cliente, um número, bem como nós mesmos.

Está mais do que na hora de explorarmos nossas percepções ambientais e voltarmos nossas lentes para os detalhes dos locais em que transitamos, aqui, no caso, o hospitalar. Precisamos ser agentes concretos de transformações, além da lógica intrínseca de qualquer sistema. A qualidade das relações humanas, suas implicações e subjetivações devem ser levadas em consideração como de suma importância na construção de um sistema para a saúde. A ferramenta indispensável para a concretização de tal obra é o próprio humano. Nossa matéria prima são os sentimentos e sensações que nos tornam vivos e conscientes dessa existência, integrados com um cosmos moldado por nossas atitudes, afetos e pensamentos. A referência que temos é o próprio cuidado, verdadeiro nó sinusal capaz de levar energia e saúde aos confins da imbricada teia que nos une.

Atitudes e mudanças de concepções de mundo são tão viáveis como qualquer pílula para aliviar a dor. A todo o momento vivemos o "vir a ser". Neste curto espaço de tempo em que transcorre a nossa existência, podemos vislumbrar um despertar para a ética do respeito mútuo a toda manifestação de vida. Para isso é preciso aflorar em nós um devir múltiplo. Para compreender, "um indivíduo, etiquetado antropologicamente como masculino, pode ser atravessado por devires múltiplos e, aparentemente, contraditórios: devir-feminino que coexiste com um devir-criança, um devir-animal, um devir-invisível, etc." (GUATTARI; ROLNIK, 2005, p. 382).

Estamos, portanto, em constante devir, o que significa que estamos em permanente transformação. Precisamos nos permitir viver essas transformações, esses movimentos. E assim descongestionar as veias e artérias de nosso corpo, para que circule a mágica de uma percepção sensível capaz de difundir a compreensão mútua dentro de nossas enfermarias. Desta forma, conseguiremos ressignificar sofrimentos e tensões na busca de relações mais saudáveis e de um cuidado mais sensível do corpo.

\section{A ética na percepção sensível do ambiente}

É fundamental um exercício constante de ressignificar o ambiente hospitalar como um lugar de vida e saúde. Essa ressignificação está conectada com a necessidade de ressingularização dos corpos e na transformação de relações instituídas em instituintes. Referindo-se a subjetividade da ressingularização, Guattari menciona a capacidade de "receber cara-a-cara o encontro com a finitude sob a forma do desejo, da dor, da morte" (1993, p. 55). Através dessa produção subjetiva é possível enfrentar os movimentos da vida de maneira a ressinguralizá-los e ressignificá-los. Ou seja, como o próprio Guattari afirma, "os indivíduos devem se tornar a um só tempo solidários e cada vez mais diferentes" (idem).

As pessoas vão ao hospital por problemas de saúde e lá precisam encontrar a pulsão da vida. Mas o que é vida? Vida são as relações, as emoções, os pensamentos, os afetos, os sentimentos, as forças de vida e morte e as forças que perpassam esses extremos. E como lidar com estas forças? Uma possibilidade é atuar a partir da percepção ambiental, da solidariedade e do cuidado que podem emanar nos estreitos abismos existentes entre a vida e a morte. Para essa percepção, solidariedade e práticas de cuidado, propomos um exercício de perspectivismo. Ou seja, coloquem-se no lugar do paciente. Como é estar no lugar do outro? 
Na tentativa de romper com a barreira dos nossos corpos podemos projetar sensações que nos sensibilizem ao cuidado. Nesse momento parece ser importante pensar na escolha profissional que fizemos. Guattari (1993) atenta, em seu livro "As três ecologias", para o cuidado com as responsabilidades assumidas. A neutralidade não existe e precisamos reconhecer em nossas escolhas os nossos compromissos éticos. Estas escolhas estão implicadas com os fazeres profissionais que desenvolvemos durante nossa existência. Isso tem conexão com o cuidado de nós mesmos, do outro, e do ambiente em que estamos inseridos, pois os movimentos resultantes dessas escolhas, sejam elas quais forem, irão reverberar no mundo.

Outra questão é: que sentimentos produzimos com essa escolha? Essa produção estética precisa ser fomentada de tal forma a ressignificar sentimentos de opressão, morte, ódio e transformá-los na produção de mais vida, mais liberdade, mais amor. Isto acontece quando damos um sorriso e percebemos que esse gesto foi capaz de mudar a reação do outro, muitas vezes transformando temor e ameaça em sentimentos de acolhimento e confiança. São coisas absolutamente simples como esta que uma educação do sensível pode promover.

Precisamos cuidar das nossas escolhas e observar como estas estão repercutindo nas outras formas de vida e existência humana e não-humana. Importante entender que esse outro a que estamos nos referindo pode ser nosso próprio planeta. Assim estamos cuidando das nossas vidas, porque cuidar do outro pode nos ajudar a cuidar de nós mesmos.

O médico Albert Schweitzer nos deixou a seguinte reflexão:

lentamente vai emergindo no pensamento humano a ideia de que a ética não se estende somente a espécie humana, como abarca também o mundo animal. Desta forma, podemos chegar a dizer que a ética é o respeito a toda vida. $(1996$, p. 88)

Essa vida a que se refere Schweitzer é o outro também, em suas mais variadas formas de existência. Nós somos o outro. Somos o outro na dor, na morte, mas na vida também e em todas as situações em que as forças da vida nos atravessam. $O$ fato é que somos uma espécie dotada de potencial transformador capaz de produzir outras formas de relações, desenvolvendo novos sentimentos e afetos para com os demais seres vivos. Certamente podemos romper com sentimentos, relações, afetos, pensamentos, enfim, com os valores produzidos e reproduzidos pelo grande capital.

Precisamos sentir a vida com nossa percepção sensível, mais aguda e refinada pelas experimentações, e para isso é necessário um exercício constante do olhar. Um olhar do cuidado, para o cuidado, um olhar para o meio ambiente que permita que, de alguma maneira, nos transformemos no ambiente em que estamos inseridos, acessando devires-animal, devirescriança, entre outros. Isto permitirá que atualizemos virtualidades, reinventando o próprio ambiente, e que transcendamos o visível para que possamos desenvolver outros canais perceptivos. Sentir o outro pode auxiliar a compreender melhor um estado de existência específico, ainda que patológico, mas que este sentir também seja capaz de nos fazer sonhar e transmutar a dor.

Além disso, é preciso colocar em movimento as relações, tanto no interior da própria equipe de saúde quanto entre esta e as pessoas que buscam cuidados no ambiente hospitalar. Isto significa irmos ao encontro de relações mais saudáveis e solidárias, relações de afeto que proporcionem a compreensão de que a escolha de atuar naquele ambiente implica necessidade constante de produzir mais vida. Trata-se de uma saúde voltada para o cuidado com as relações. Um afeto colaborativo pela vida, assumindo o papel ético da responsabilidade de fazer brotar essa vida no lugar da morte e a solidariedade no lugar dos individualismos. Vivemos a todo instante e 
morremos a todo instante. $\mathrm{O}$ que fazemos com isto? Como ressignificar e ressingularizar esse dualismo para além dele mesmo, num rizoma de possibilidades para restabelecer novos modos de vida?

O exercício de um novo olhar e de uma nova forma de cuidado precisa estar presente não só nos hospitais como também nos diversos espaços de convívio, no dia a dia das pessoas, rompendo com as rígidas fronteiras do instituído, com papéis e representações sociais. Para isso, precisamos reinventar nossas relações e descobrir a vida que flui por traz de máscaras e rótulos, estabelecendo novas relações com as pessoas e não com os clientes, com as pessoas e não com os pacientes. Precisamos dar um sentido para "o cuidar" que não seja apenas a mera reprodução de procedimentos técnicos visando o bem-estar do corpo físico.

\section{Intervenção institucional - experimentações estéticas em educação ambiental}

Ao colocarmos o corpo como objeto de análise é preciso avançar com relação a uma abordagem mais ampla, multiprofissional e transdisciplinar. Tanto os instrumentos metodológicos quanto os dispositivos cênico e audiovisual utilizados em uma intervenção de educação ambiental (fig. 1) no Hospital Universitário da Universidade Federal do Rio Grande - FURG durante a 35a Semana Riograndina de Enfermagem da FURG (2011), revelaram limites e possibilidades no que diz respeito ao corpo humano: corpos-mutantes com extraordinária capacidade de adaptação ao meio e, concomitantemente, de transformação de si e do ambiente em que está inserido.

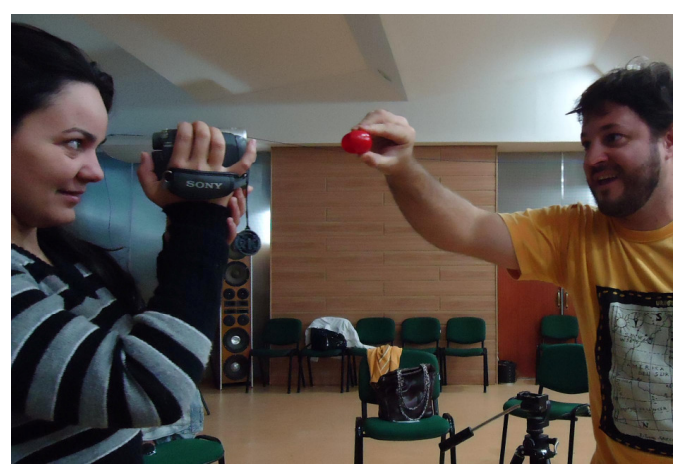

Figura 1 - Oficina Experimentações Estéticas: clownificando o ambiente hospitalar, 2011 Fonte: acervo dos oficineiros

Esse processo de experimentação vem indicando que a verdade não está fixada de uma vez por todas, não é definitiva e nem universal. As intervenções socioambientais no ambiente hospitalar colocam em crise formas instituídas, ou seja, tudo aquilo que é tomado como algo que "sempre foi e sempre será assim" - inclusive o próprio corpo.

A concepção de Homem Total desenvolvida pelo antropólogo Marcel Mauss (1974), na tese "As Técnicas Corporais", nos dá outra referência. Ele alega que para entendermos o corpo é preciso introduzir uma tríplice análise, é necessário avaliar as condições psicológicas, fisiológicas e sociais que constituem o humano.

A posição dos braços, das mãos caídas enquanto se anda, formam uma idiossincrasia social, e não simplesmente um produto de não sei que agenciamentos e mecanismos puramente individuais, quase que inteiramente psíquicos. Exemplo: creio poder reconhecer também uma moça que tenha sido educada em um convento. Ela anda, geralmente, de punhos fechados... Existe, portanto, igualmente uma educação do andar. 


\section{Monografias Ambientais issN: 2236-1308}

(...) Há, pois, coisas que acreditamos ser de ordem hereditária, mas que, na realidade, são de ordem fisiológica, psicológica e sociológica. Certa forma dos tendões, e mesmo dos ossos, não é outra coisa senão a decorrência de certa forma de se comportar e de se dispor. (MAUSS, 1974, p. 214 e 220).

Mauss faz entrarmos em contato com a complexidade do corpo humano. Para ele, não existe corpo subtraídas as condições histórico-geográficas que o constituem. Por isso, é importante investigarmos as condições ambientais em que o corpo emerge, ou seja, os elementos que determinam a expressão dos corpos, a forma de perceber a realidade. Enfim, as condições ambientais que determinam a morfologia e a funcionalidade do corpo.

O corpo pode ser ensinado a modificar sua postura, a sentir, agir e reagir, amar, lutar, criar soluções, expressar-se, produzir outros mundos, novas possibilidades de existência. O humano, diferentemente de outras espécies, possui a capacidade de intervir racionalmente sobre si mesmo, de configurar (e reconfigurar) a si próprio, e essa ação só pode ser compreendida do ponto de vista da relação corpo-ambiente e seus mútuos engendramentos.

Tudo leva a crer que é necessário perseverar, colocar a dinâmica espontânea dos corpos no fluxo dos acontecimentos (fig. 2), transitar no limiar do inumano, experimentar as intensidades do processo, deslocar-se de um ponto singular a outro. Isso tem nos feito pensar que o extraordinário da vida está contido no ordinário e vice-versa, que o sobrenatural contém e está contido no natural.

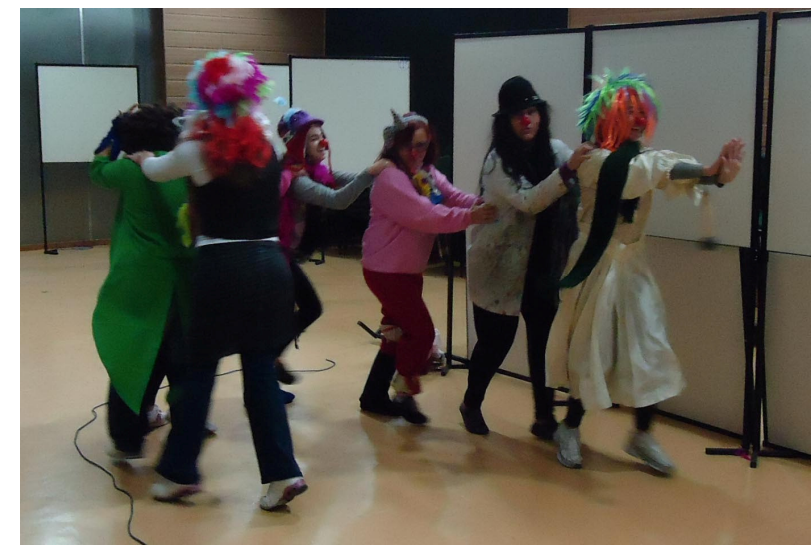

Figura 2 - Oficina Experimentações Estéticas: clownificando o ambiente hospitalar, 2011 Fonte: acervo dos oficineiros

\section{Vivendo a saúde, criando novas fronteiras...}

Parece relevante promover ações que impliquem a capacidade de sonhar e criar com outrem, independentemente do ambiente em que estejamos inseridos. Empreendimentos que objetivem a qualidade de vida global, que busquem a saúde por meio de estudos, diagnósticos e tratamentos da área médica, mas que também utilizem em favor da manutenção da saúde os diversos tipos de conhecimentos produzidos pelo humano: artístico, mitológico, filosófico, etc.

Para isso, talvez necessitemos pensar a aprendizagem como um conjunto de práticas e conhecimentos capazes de prevenir e/ou minimizar a doença. Um diagnóstico médico bem elaborado pode ser capaz de definir, com precisão, onde está localizado o foco da doença e sua provável causa. Em outros termos, é possível dizer que as ciências médicas desenvolveram métodos, técnicas e substâncias capazes, em diversos casos, de restituir a saúde.

Embora a definição de saúde varie muito de cultura para cultura, a ideia do "bem-funcionar do organismo como um todo" perpassa diversas concepções médicas a respeito do tema. 0 
REMOA

\section{Monografias Ambientais issv: 2236-1308}

organismo saudável realiza aspirações, satisfaz necessidades, intervém adequadamente no meio ambiente, interage com outros organismos, extrapola a concepção de um todo organizado mecanicamente.

O trabalho de experimentação cumpre, assim, suas metas fundamentais quando atua em regiões fronteiriças, quando instiga o pensamento colocando em movimento saberes que instrumentalizam ações necessárias. A criação conceitual tem que ser impulsionada pela necessidade materializada, pulsante, experimentada. Filosofar é pensar, agir, transformar, desterritorializar, criar novas fronteiras, outros mundos.

\section{Referências}

GUATTARI. As três ecologias. Campinas: Papirus, 1993.

GUATTARI, Félix; ROLNIK, Suely. Micropolítica: cartografias do desejo. Petrópolis: Vozes, 2005.

MAUSS, Marcel - Sociologia e Antropologia Volume II - Introdução de Claude Lévi-Strauss, São Paulo, EPU, 1974.

VILARÓ, Carlos Páez. Albert Schweitzer em el reino de los Galoas. Montevideo: Artes gráficas integradas SRL, 1996. 